WS5-B03

\title{
Mineralization Indicators from Seismic and Full Wave Sonic Data in the Athabasca Basin, Saskatchewan, Canada
}

\author{
Z. Hajnal* (University of Saskatchewan), E. Takacs (University of \\ Saskatchewan) \& B. Pandit (University of Saskatchewan)
}

\section{SUMMARY}

Seismic reflection method was successfully introduced, as an exploration tool, in the Athabasca Basin in 2003. Investigations demonstrated that the mineralized zones are associated with basement located shear zones, complex variable sandstone-basement unconformity intervals, and significant alteration zones within the sandstone fill and the basement. All these anomalous zones consistently were associated with diagnostic seismic images, providing a set of primary indicators of mineralization for regions of future exploration interest. Recent Full Wave Sonic surveys illustrated that not only the longitudinal (P) waves, which were exclusively utilized to date, but detectable transverse waves (S) can also observed from the geologic setting of the basin. In most instances, the responses of these elastic disturbances, to geologic irregularities, are recognizably dissimilar. This duality of the specific responses permits derivation of characteristic elastic properties of the lithological units within the investigated area. The knowledge of the depth variations of the $\mathrm{P}$ and $\mathrm{S}$ wave velocities permits the computations of elastic parameters of rocks such as shear modulus $(\mu)$, Lame's modulus $(\lambda)$ and Poisson's ratio $(\sigma)$. Combinations of these elastic properties facilitate the recognition of fractures with different sizes and their properties, as well as alteration and meta-somatic zones. 


\section{0 \\ Amsterdam ' 14}

\section{Introduction}

In search for mineral deposits seismic reflection studies are successfully conducted at several locations in the Athabasca Basin, Canada. Seismic images clearly define the subsurface structural environments and the unconformity contacts (UC) between the Proterozoic basin fill and the underlying crystalline basement. Appropriate basement structures and signatures of the UC are primary indicators of mineralization. Beyond the imaging capability of the seismic signals, the connate rock properties are effectively exploited to provide vital and detailed geologic information in younger sedimentary environments. A unique surface and borehole data set from old hard rock terrains presented an opportunity to investigate the potential exploration-related relevance of these intrinsic properties of seismic data.

\section{Investigations}

As expected, the advanced continuous wavelet transformed seismic section of Line-4 reveals the nonreflective characteristics of the sandstone cover above the UC (Figure 1). The complexity of the UC transition zone is imaged in detail. The original contact interval is characterized by a multi-phased complex waveform. The strong UC signatures define a prominent, major fold structure. On the left third of the section, the seismic images reveal a paleochannel defining a younger, less reflective UC interface above the original UC. The white continuous lines mark the reactivated segments of the original Hudsonian thrust sheets. The yellow dashed lines map the later phases of brittle deformation. Several holes tested the seismic results and confirmed the seismic model. The deepest hole KEF-12$08(552 \mathrm{~m})$ recognized the strong southeast dipping reflections below the UC as a mylonized shear zone with pegmatite intrusions. Core sample chemical analysis defined distinct boron and potassium anomalies coincidental with the UC, suggesting influences of metasomatic processes along the interface and potential connection between alterations and the quality of the seismic signatures.

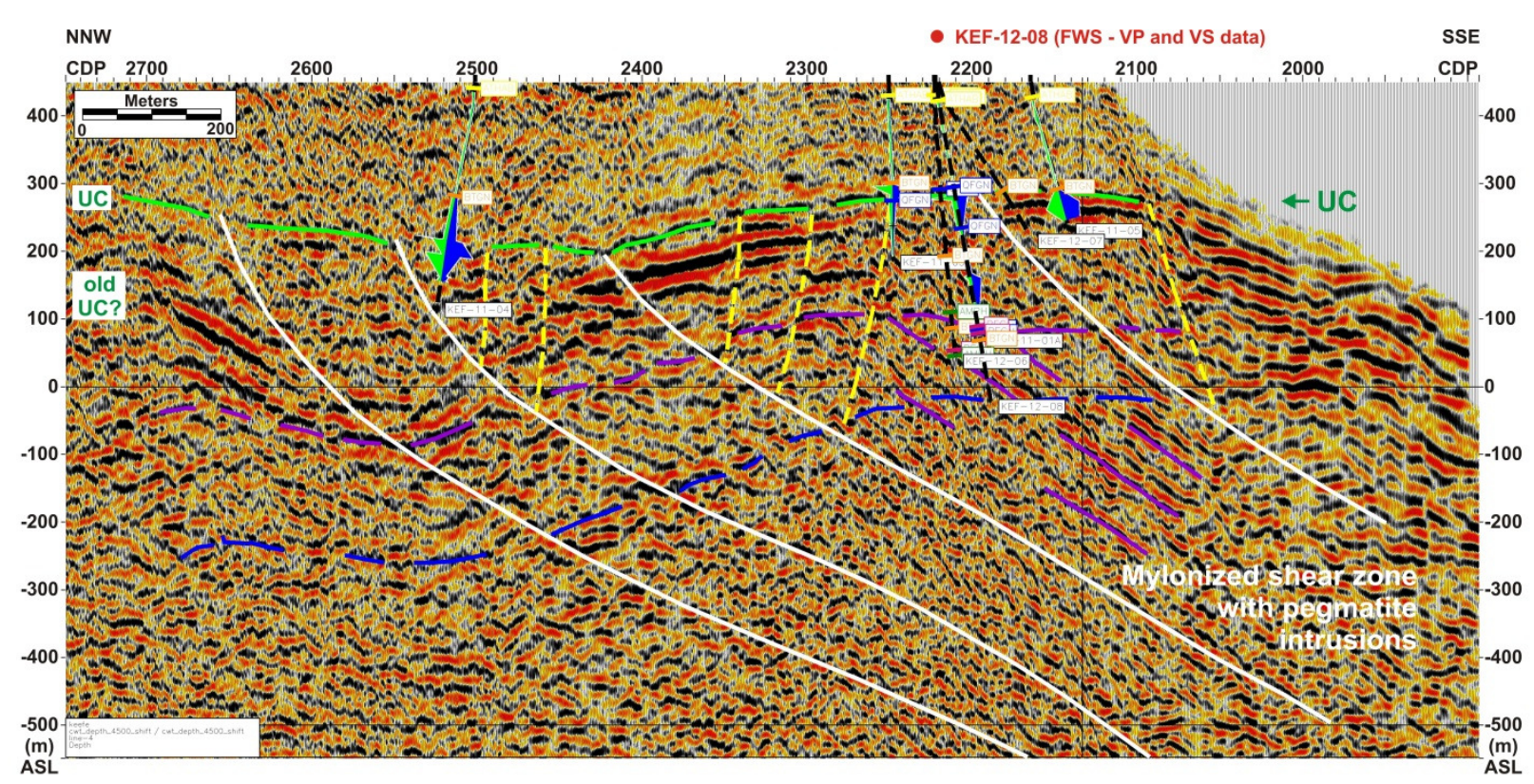

Figure 1 Keefe Lake high-resolution seismic section (south part of Line-4) with inserted boron (green) and potassium (blue) logs and detailed interpretation. Green horizon: UC; purple horizon: pegmatite?; blue horizon: folded structure inside the basement. White and yellow lines: interpreted fault systems.

In recent years, novel successful developments have taken place in extraction of comprehensive subsurface petrophysical (lithology variations, structural framework, fractural complexity, clay/fluids) information from the combined analyses of Full Wave Sonic (FWS) borehole data or surface derived longitudinal and shear wave data (Goodway, 2001; Russell and Hampson, 2006). 


\section{Amsterdam ' 14}

Once the three fundamental elastic properties, namely compressional wave velocity $V_{P}$, shear wave velocity $\mathrm{V}_{\mathrm{S}}$ and density $\mathrm{Rho}[\rho]$ are available, several primary petrophysical parameters can be derived. The $\mathrm{V}_{\mathrm{P}} / \mathrm{V}_{\mathrm{S}}$ ratio is a measure of rock behavior under elastic deformation and this information is also utilized to determine the Poisson's ratio $[\sigma]$ which is the measure of the behavior of the rock under longitudinal and transverse stresses. Lambda (Lame $[\lambda]$ parameter) does not represent a distinct elastic property but it is a sensitive measure of elastic response under compressive stress. $\mathrm{Mu}[\mu]$ is a characteristic parameter of the stiffness of the rocks under shear stress. Recent investigations illustrate also that all of these mechanical parameters $[\rho, \sigma, \lambda, \mu]$ have characteristic rock attribute properties. Displays of their combined, interconnected relationships (cross-plots) are more demonstrative of the distinct lithologies than their individual values by themselves. Goodway (2001) provides a useful new insight into the significance of these moduli and points out that $\lambda$ and $\mu$ play a more unique role in the bound elastic deformation processes than they were recognized previously. Therefore their anomalous behaviors are more effectively identifiable with changes in lithology, porosity/fracture or clay/fluid content.

The Poisson's ratio versus $\mathrm{V}_{\mathrm{P}}$ cross-plot yields several clusters): 1. Undisturbed, sandstone lithology; 2. UC/transition zone; 3. Undisturbed basement lithology; 4. Open fractured basement intervals; 5. Fractured basement with clay alteration. Identification of the points of the clusters on the borehole logs (lower part of the figure) helps to establish the depths of the anomalous intervals and the dimensions of the anomalous zones. The type of clay alterations can then be investigated from the core sample data. The appropriate levels and complexities of the fracture zones and the desired types of clay alterations are primary indicators of mineralization.

\section{Conclusions}

Seismic reflection surveys provide distinct images of both major basement and younger, mainly brittle deformation related structural disturbances. These structural zones provided the pathways for fluid migration during the depositional periods of mineralization. The highly detailed structural images, recognized in boreholes, and their acoustic responses indicate, that increase of the seismic signal spectrum of the surface seismic investigations would provide significant improvement in mapping of anomalous zones both in the sandstone and the basement.

Observation of longitudinal and transverse waves either in boreholes or by surface means open up vital opportunities to study anomalous changes in lithology, fractural configurations and their properties, and alterations. Appropriate changes and their combined alignments are primary indicators of mineralization. Changes in sonic velocities, resistivity, in response to $\mathrm{U}$ mineralization were observed at several depth intervals in both sandstone and basement rocks. An attempt has to be made to establish the corresponding changes in velocities to changes in the level of alterations in the primary rock masses. This investigation suggests that, correlation of corresponding attributes in nearby boreholes can establish spatial trends of anomalous changes in primary indicators of mineralization.

\section{Acknowledgement}

Contributions by Athabasca Uranium Inc. have permitted the extension of limited experiments to broader, more effective, multi-faceted investigations. Special thanks to Advanced Logic Technology (WellCAD) for their generous software support.

\section{References}

Goodway, B. [2001] AVO and Lame constants for rock parameterization and fluid detection, CSEG Recorder, 35-60.

Russell, B. and Hampson, D. [2006] The old and the new in seismic inversion. CSEG Recorder, 5-11. 